Article

\title{
Characterization of Two Pseudomonas aeruginosa Viruses vB_PaeM_SCUT-S1 and vB_PaeM_SCUT-S2
}

\author{
Yangyijun Guo, Ping Chen, Zhanglin Lin * and Tingting Wang *(D) \\ School of Biology and Biological Engineering, South China University of Technology, 382 East Outer Loop Road, \\ Higher Education Mega Centre, Guangzhou 510006, China; 201620133950@mail.scut.edu.cn (Y.G.); \\ chenp211@scut.edu.cn (P.C.) \\ * Correspondence: zhanglinlin@scut.edu.cn (Z.L.); wangtt@scut.edu.cn (T.W.); Tel.: +86-20-3839-0639 (T.W.)
}

Received: 5 January 2019; Accepted: 28 March 2019; Published: 1 April 2019

\begin{abstract}
The sophisticated antibiotic resistance mechanism of Pseudomonas aeruginosa has urged the development of alternative antibacterial strategies. Phage therapy has been proven successful for the treatment of multidrug-resistant infections. In this study, we reported two virulent $P$. aeruginosa phages, vB_PaeM_SCUT-S1 (S1) and vB_PaeM_SCUT-S2 (S2), which were characterized at morphological, genomic, and proteomic levels. Phages S1 and S2 were assigned to the Myoviridae family. The genome sequencing showed that the genome size of Phage S1 was 66,046 bp and that of Phage S2 was $94,434 \mathrm{bp}$. The phylogenetic tree indicated that the two phages were distantly related to each other and were classified in the genera Pbunavirus and Pakpunavirus respectively. Thirty-one proteins were identified for each phage by mass spectrometry and were used to substantiate the function of the predicted coding genes. The two phages inhibited the growth of P. aeruginosa strain PAO1 at low multiplicity of infection levels and had good performance both on preventing biofilm formation and eradicating preformed biofilms. They were also stable over a wide range of temperature and $\mathrm{pH}$ values, supporting their potential use in the treatment of $P$. aeruginosa infections.
\end{abstract}

Keywords: Pseudomonas aeruginosa; phage therapy; Myoviridae; complete genome; proteomics; one-step growth curve; lysis kinetics; biofilm

\section{Introduction}

The recent emergence and the expanding distribution of multidrug-resistant (MDR), extensively drug-resistant, and pandrug-resistant bacterial strains have been a great challenge for public health due to the lack of effective antibiotic treatments. In particular, the ESKAPE organisms (Enterococcus faecium, Staphylococcus aureus, Klebsiella pneumoniae, Acinetobacter baumannii, Pseudomonas aeruginosa, and Enterobacter species) are the dominant causes of serious nosocomial infections [1-3]. As a ubiquitous Gram-negative opportunistic bacterium, P. aeruginosa can cause life-threatening infections in patients suffering from cystic fibrosis, severe burns, and other immunocompromising conditions, leading to considerable morbidity and mortality [4,5]. Unfortunately, MDR P. aeruginosa is difficult to eradicate by conventional antibiotics, owing to its sophisticated antibiotic resistance mechanisms, which includes intrinsic and acquired drug resistance, and its capacity to form biofilms [6-8]. Thus, there is an urgent demand for the development of alternative antibacterial strategies to combat these superbugs [9].

The interest in phages, which have been recognized as antimicrobial therapeutics for nearly a century, has recently resurged because of their high specificity and abundance [10-13]. Bacteriophages are natural predators of bacteria and are classified as virulent (lytic) phages or temperate (lysogenic) phages depending on their distinct life cycle. However, only virulent phages have been explored for phage therapy, mainly because temperate phages are associated to potential problems originating from their ability of transferring DNA between different host bacteria and the possible alteration of 
their host pathogenicity when shifting from quiescent state to lytic state [14,15]. Phage therapy has been proved a successful treatment option, not only in animal models [16] but also in human clinical trials [17]. Due to the high specificity of phages for a determined host, phage cocktails are often utilized in order to broaden the antibiotic spectrum of the therapy, which makes a request for exploiting and characterizing more therapeutic phages.

Recent advances in genome sequencing and biotechnology have greatly promoted the discovery and identification of numerous novel phages [18]. As for December 2018, the Genebank database has deposited 323 Pseudomonas phage genome sequences, among which more than two-thirds were P. aeruginosa phages. In order to be considered eligible for their use in phage therapy, P. aeruginosa-specific phages must be fully characterized to ensure that they are safe, i.e., their genomes must be studied in detail to prove the lack of genes encoding for toxins, virulence factors or other undesirable genes, through complete genome sequencing $[19,20]$. In this study, we characterized two P. aeruginosa phages, vB_PaeM_SCUT-S1 (Phage S1) and vB_PaeM_SCUT-S2 (Phage S2), at morphological, genomic, and proteomic levels. The two phages were new members of the genera Pbunavirus and Pakpunavirus, respectively, and their therapeutic potentials were investigated for the growth inhibitory effects on the planktonic cells and biofilm cells.

\section{Materials and Methods}

\subsection{Bacterial Strains and Culture Conditions}

The bacterial strains used in this study are listed in Table S1. P. aeruginosa ATCC 9027, ATCC 15442, ATCC 27853, and Stenotrophomonas maltophilia ATCC 51331 were purchased from Guangdong Microbial Culture Center, China (GDMCC). The strains PALWL1.001, PALWL1.002, and PALWL1.003 were collected by our laboratory. Strain PAO1 was a gift from Prof. Hu (Third Military Medical University, Chongqing, China). All bacterial strains and phages were routinely cultured at $37^{\circ} \mathrm{C}$ in lysogeny broth (LB) containing $2 \mathrm{mM} \mathrm{CaCl}_{2}$. Phage plating was performed using the overlay agar method, with LB containing $0.6 \%$ and $1.5 \%$ agar used for the top and the base agar, respectively.

\subsection{Bacteriophage Isolation, Propagation, and Purification}

Phages were isolated by following the enrichment method using strain PAO1 as the host [21,22].

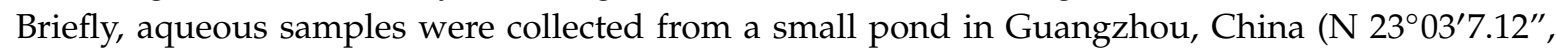
E $\left.113^{\circ} 04^{\prime} 5.35^{\prime \prime}\right)$. After centrifugation for $10 \mathrm{~min}$ at $9000 \times g$, the supernatant was filtered through a $0.45 \mu \mathrm{m}$ filter and incubated with the host strains for $24 \mathrm{~h}$ at $37^{\circ} \mathrm{C}$. The bacterial cell debris was removed by centrifugation and filtration, and the supernatant was plated using the overlay agar method to check the host lysis. Twelve candidate plaques obtained were scraped with pipette tips and resuspended in SM buffer ( $100 \mathrm{mM} \mathrm{NaCl}, 8 \mathrm{mM} \mathrm{MgSO}_{4}$, and $50 \mathrm{mM}$ Tris-HCl, pH 7.5), were then diluted 1000-fold in the same buffer, and purified by repeated co-culturing with the host strains using the overlay agar method (three rounds). The uniqueness of the phages was confirmed by analysis of the genome restriction maps obtained using three endonucleases (HindIII, EcoRI or XbaI) individually. Only two different phages were identified.

The phage propagation was performed according to the classic procedure [23]. An aliquot of $500 \mathrm{~mL}$ of PAO1 culture (oa. OD 0.4-0.6 at $600 \mathrm{~nm}$ ) was infected by the pure phage stocks and grown overnight. Subsequently, $10 \mathrm{~mL}$ of chloroform were added, and the cells were incubated with shaking for $10 \mathrm{~min}$ at $37^{\circ} \mathrm{C}$ to obtain the lysates. The genomic DNA of the host was removed by the treatment of $1 \mu \mathrm{g} / \mathrm{mL}$ DNase I and RNase for $30 \mathrm{~min}$ at room temperature. The lysate was then supplemented with a final concentration of $1 \mathrm{M} \mathrm{NaCl}$ and incubated for $1 \mathrm{~h}$ at $4{ }^{\circ} \mathrm{C}$. After incubation and centrifugation, the supernatant was supplemented with $10 \%(w / v)$ PEG 8000 and stored at $4{ }^{\circ} \mathrm{C}$ overnight to precipitate the phage particles. After centrifugation $(11,000 \times g, 10 \mathrm{~min})$, the pellets were suspended in SM buffer and an equal volume of chloroform was added to extract the PEG and the bacterial debris. After centrifugation at $3000 \times \mathrm{g}$ for $15 \mathrm{~min}$ at $4{ }^{\circ} \mathrm{C}$, the suspension was adjusted by adding $\mathrm{CsCl}$ reagent to a 
density of $1.15 \mathrm{~g} / \mathrm{mL}$ and carefully loaded on a $\mathrm{CsCl}$ density gradient consisting of the step gradient $1.35 \mathrm{~g} / \mathrm{mL}, 1.5 \mathrm{~g} / \mathrm{mL}$, and $1.7 \mathrm{~g} / \mathrm{mL}$. After ultracentrifugation at $87,000 \times \mathrm{g}$ for $2 \mathrm{~h}$ at $4{ }^{\circ} \mathrm{C}$, the band of phage particles was collected and dialyzed twice for $1 \mathrm{~h}$ at $4{ }^{\circ} \mathrm{C}$ against a 500 -fold volume of SM buffer to remove the remaining $\mathrm{CsCl}$.

\subsection{Host Range Analysis}

Host range analysis was performed using the spot testing method [24] on three biological replicates. Briefly, $10 \mu \mathrm{L}$ of phage suspensions of six concentrations ranging from $10^{4}$ to $10^{9} \mathrm{pfu} / \mathrm{mL}$ were spotted onto bacterial lawns and incubated at $37^{\circ} \mathrm{C}$ for $24 \mathrm{~h}$. After incubation, the spot morphology was observed and classified as " $\mathrm{C}+++$ ", a large lysis zone at $10^{2} \mathrm{pfu}$; “ $\mathrm{C}++$ ", individual plaques at $10^{2}-10^{3}$ $\mathrm{pfu}$; “C+", individual plaques at $10^{4}-10^{5} \mathrm{pfu}$; “ $\mathrm{T}$ ", a turbid lysis zone at $10^{6}-10^{7} \mathrm{pfu}$; "-", no lysis.

\subsection{Electron Microscopy}

For electron microscopy, the CsCl-purified phages were spotted onto 400 mesh carbon-coated grids and negatively stained with $2 \%$ phosphotungstic acid ( $\mathrm{pH}$ 6.5) [25]. The grids were observed by a Hitachi transmission electron microscope at $80 \mathrm{kV}$. The dimensions of three viral particles of each phage was measured, and the values were averaged.

\subsection{Temperature and $p H$ Stability}

The thermal stability testing was performed by incubating the phages $\left(10^{6} \mathrm{pfu} / \mathrm{mL}\right)$ at different temperature for $1 \mathrm{~h} \mathrm{[26],} \mathrm{the} \mathrm{phage} \mathrm{titers} \mathrm{were} \mathrm{then} \mathrm{determined} \mathrm{by} \mathrm{using} \mathrm{the} \mathrm{double-layer} \mathrm{overlay}$ method. The relative titer was calculated as the ratio of phage titers at a different temperature to those stored at $4{ }^{\circ} \mathrm{C}$. For the $\mathrm{pH}$ stability analysis, the phages $\left(10^{6} \mathrm{pfu} / \mathrm{mL}\right)$ were diluted 100 -fold with $\mathrm{SM}$ buffer of different $\mathrm{pH}$ values and incubated for $1 \mathrm{~h}$ at room temperature. The relative titer was calculated as the ratio of phage titers treated with different $\mathrm{pH}$ levels to those by the original SM buffer ( $\mathrm{pH}$ 7.5). Three independent experiments were performed.

\subsection{Genome DNA Extraction and Sequencing}

The genomic DNA was extracted as follows [23,27]. The purified phage was first treated with $2.5 \mathrm{U} / \mathrm{mL}$ DNase I and incubated at $37^{\circ} \mathrm{C}$ for $1 \mathrm{~h}$ to remove the host DNA. Next, 0.1 volumes of $2 \mathrm{M}$ Tris- $\mathrm{HCl}$ ( $\mathrm{pH}$ 8.5)/0.2 M EDTA, 0.01 volumes of $0.5 \mathrm{M}$ EDTA ( $\mathrm{pH} 8.0$ ), and 1 volume of formamide were added, and the solution was incubated for $30 \mathrm{~min}$ at room temperature. The raw genomic DNA was precipitated adding 2 volumes of $100 \%$ ethanol followed by centrifugation at $9000 \times g$ for $20 \mathrm{~min}$ at $4{ }^{\circ} \mathrm{C}$. The DNA pellet was washed twice with $70 \%$ ethanol and suspended in $567 \mu \mathrm{L}$ of TE buffer (10 mM Tris-HCl, $1 \mathrm{mM}$ EDTA) and added with $30 \mu \mathrm{L}$ of $10 \%(w / v)$ SDS and $3 \mu \mathrm{L}$ of $20 \mathrm{mg} / \mathrm{mL}$ proteinase $\mathrm{K}$. The mixture was incubated for $1 \mathrm{~h}$ at $50^{\circ} \mathrm{C}$. Subsequently, $100 \mu \mathrm{L}$ of $5 \mathrm{M} \mathrm{NaCl}$ and $80 \mu \mathrm{L}$ of $\mathrm{CTAB}$ (cetyltrimethylammonium bromide)/ $\mathrm{NaCl}$ solution were added and incubated for $10 \mathrm{~min}$ at $65{ }^{\circ} \mathrm{C}$. Next, the mixture was sequentially treated with one volume of chloroform, one volume of phenol/chloroform/isoamyl alcohol (25:24:1), and one volume of chloroform, to gradually purify the genomic DNA. The aqueous phase was collected, and 0.7 volumes of isopropanol were added to precipitate the DNA. After centrifugation at $13,000 \times g$ for $15 \mathrm{~min}$ at $4{ }^{\circ} \mathrm{C}$, the purified DNA pellet was washed twice with $500 \mu \mathrm{L}$ of ice-cold $70 \%$ ethanol and left to dry. The air-dried pellets were suspended in $20 \mu \mathrm{L}$ TE. The DNA concentration was measured by a Nanodrop2000 (Thermo Fisher Scientific, Waltham, MA, USA). The purified DNA was used for the whole genome sequencing by Personal Biotechnology Corp. (Shanghai, China). A DNA library with an insert size of $400 \mathrm{bp}$ was prepared for each sample. The two phage samples were sequenced by an Illumina MiSeq platform using the PE 250 bp strategy. 


\subsection{Genome Assembly, Annotation, and Comparison}

After filtering the raw reads to remove the adaptor contamination (i.e., low-quality reads with ' $\mathrm{N}$ ' bases), the remaining high-quality reads were assembled by ABYSS 2.0.2 [28] and MIRA 4.0 [29]. The contigs were manually assembled based on overlaps of more than $40 \mathrm{bp}$ to obtain the final scaffold. Next, the coverage was visualized using Geneious 10.2.3 to identify the genome termini, and the results were confirmed using PhageTerm [30], which is available on the public Galaxy server (http://galaxy.pasteur.fr/). After the whole genome sequences were obtained, the annotation was carried out using RAST [31-33], Glimmer [34], and GeneMarkS [35], then was subsequently manually confirmed. In addition, tRNAs were predicted by tRNA-Scan [36] and ARAGORN (http://mbio-serv2.mbioekol.lu.se/ARAGORN/). The complete genome sequences of Phages S1 and S2 were searched for similarity against the reported genomes by BLASTN https://www.ncbi.nlm.nih.gov/BLAST/). Next, the genomes of the five most similar phages were re-annotated by the same procedure as that of the two phages, and the transcribed ORF sequences were compared by BLASTP. Comparative analysis of the whole genomes was performed by MAFFT [37]. The conserved sequences were extracted by Gblocks [38] and then used to construct a maximum likelihood tree by RAxML [39]. The phylogenetic trees based on the amino acid sequences of the terminase large subunit were constructed using Molecular Evolutionary Genetic Analysis (MEGA) 7.0 [40]. All the phylogenetic trees were visualized by MEGA 7.0.

\subsection{Proteomics Analysis}

The structural proteins of the phages were analyzed after removing the DNA, as previously described [41]. Briefly, the purified phage particles were mixed with an equal volume of $10 \mathrm{M} \mathrm{LiCl}$ and incubated for $10 \mathrm{~min}$ at $46^{\circ} \mathrm{C}$. Next, the mixture was diluted 10 -fold with SM buffer, followed by $10 \mathrm{mM} \mathrm{MgCl}$ and $50 \mathrm{U}$ DNase I per $10^{12}$ pfu. After $2 \mathrm{~h}$ incubation at $37^{\circ} \mathrm{C}$, the "ghost" particles were precipitated by ultracentrifugation at $100,000 \times \mathrm{g}$ at $4{ }^{\circ} \mathrm{C}$ for $30 \mathrm{~min}$. Subsequently, the phage pellet was suspended in protein loading buffer and denatured at $95^{\circ} \mathrm{C}$ for $10 \mathrm{~min}$. The phage proteins were separated on a 12\% SDS-PAGE gel and stained with Coomassie Brilliant Blue. For the protein identification, the whole gel lane was cut, and the peptide mixture obtained by in-gel trypsin digestion was analyzed by nanoLC-MS/MS (Eksigent nanoLC-Ultra 2D and TripleTOF 5600, AB SCIEX). The MS/MS data were analyzed by MASCOT (http://www.matrixscience.com/) using the predicted proteins of Phage S1 or S2 as the databases. The phage proteins were identified using a minimum threshold of two peptides per protein.

\subsection{One-Step Growth Curve and Lysis Kinetics}

A $0.1 \mathrm{~mL}$ aliquot of phage suspension $\left(10^{7} \mathrm{pfu} / \mathrm{mL}\right)$ was added to $9.9 \mathrm{~mL}$ of mid-log-phase bacterial culture of host strain PAO1 (ca. $\mathrm{OD}_{600} \sim 0.5$ ) and incubated for $5 \mathrm{~min}$ [42]. Phage titers were detected by collecting samples at 5 - or 10-min intervals and plating them immediately by the overlay method. The average burst size was quantified as the difference between the final and the initial phage titer divided by the initial phage titer.

To measure the lytic kinetics, phages with varying multiplicity of infection (MOI) in the range 0.01-100 were incubated with mid-log-phase bacterial cultures of host strain PAO1 (ca. $\mathrm{OD}_{600} \sim 0.5$ ) in 96-well microtiter plates at $37^{\circ} \mathrm{C}, 180 \mathrm{rpm}$. The kinetic data were obtained by monitoring the change of absorbance at $600 \mathrm{~nm}$ for $20 \mathrm{~h}$ with intervals of $30 \mathrm{~min}$ using a microplate reader (Tecan infinite M200PRO, Zürich, Switzerland).

\subsection{Biofilm Inhibition Assays}

Biofilms were grown in 96-well microplates as previously described [43], with slight modifications. Briefly, an overnight-grown PAO1 culture was diluted 1:100 with fresh tryptic soy broth medium (TSB, $17 \mathrm{~g}$ of pancreatic digest of casein, $3 \mathrm{~g}$ of papaic digest of soya bean, $5 \mathrm{~g}$ of $\mathrm{NaCl}, 2.5 \mathrm{~g}$ of $\mathrm{K}_{2} \mathrm{HPO}_{4}$, and 
$2.5 \mathrm{~g}$ of glucose monohydrate for a $1 \mathrm{~L}$ solution, with a final $\mathrm{pH}$ adjusted to 7.3 ), and $150 \mu \mathrm{L}$ aliquots of this diluted culture were transferred into the wells of round-bottomed microplates (polystyrene) and incubated under a static condition at $37^{\circ} \mathrm{C}$. To analyze the capacity of preventing biofilm formation, $50 \mu \mathrm{L}$ of phage suspensions (approximately $10^{8} \mathrm{pfu} /$ well) in TSB medium or $50 \mu \mathrm{L}$ of TSB medium without phages as the controls were added to each well, and the plates were incubated for different time periods $(4,8$, and $24 \mathrm{~h})$. To analyze the capacity of removing preformed biofilms, the plates were incubated for $24 \mathrm{~h}$ to form the biofilms and rinsed three times with $0.9 \% \mathrm{NaCl}$ to remove the planktonic cells. Next, $200 \mu \mathrm{L}$ of phage suspensions (approximately $10^{8} \mathrm{pfu} /$ well) in TSB medium, or $200 \mu \mathrm{L}$ of TSB medium without phages as the controls, were added to each well and were incubated at $37^{\circ} \mathrm{C}$ for different time periods $(4,8$, and $24 \mathrm{~h})$. The plates were all washed three times with $0.9 \% \mathrm{NaCl}$ for the next assays.

CV (crystal violet) staining or XTT assay was performed to evaluate the biofilm conditions. For the CV staining, the biofilms were stained with $220 \mu \mathrm{L}$ of $0.1 \%$ crystal violet solution for $10 \mathrm{~min}$, then washed three times with $0.9 \% \mathrm{NaCl}$ to remove the excess of $\mathrm{CV}$, and left to dry in the air. Next, $220 \mu \mathrm{L}$ of $30 \%$ acetic acid were added to dissolve the bound CV. The eluted stain was transferred into another microplate, and the absorbance was measured at $590 \mathrm{~nm}$ [44]. For the XTT assay, $220 \mu \mathrm{L}$ of a solution containing $0.5 \mathrm{mg} / \mathrm{mL} \mathrm{XTT}$ and $50 \mu \mathrm{M}$ menadione were added to the wells containing the rinsed biofilms. After incubation in the dark for $2 \mathrm{~h}$ at $37^{\circ} \mathrm{C}$, the solution was then transferred into another microplate to measure the absorbance at $460 \mathrm{~nm}$ [45].

\subsection{Accession Number}

The whole genome sequences of phage vB_PaeM_SCUT-S1 and vB_PaeM_SCUT-S2 were deposited in GenBank under the accession number MK340760 and MK340761, respectively.

\section{Results}

\subsection{Isolation and Characterization of the Phages}

Using P. aeruginosa PAO1 as the host strain, we isolated two phages from aquatic environment samples. Both the phages formed clear plaques in the double agar layer lawn (Figure S1), which indicated they were virulent phages. The spotting test showed that the two phages could infect most P. aeruginosa strains with large and clear lysis zones (Table S1). From the electron microscopic imaging, it was observed that both phages had icosahedral heads and contractile tails (Figure 1a,b), which suggested that they both belonged to the order Caudovirales and the Myoviridae family. Thus, we designated them as vB_PaeM_SCUT-S1 and vB_PaeM_SCUT-S2 (hereinafter referred to as S1 and S2, respectively) according to the ICTV nomenclature for virus. Phage S1 had a capsid size of $77 \pm 2 \mathrm{~nm}$ in diameter and a tail length of $154 \pm 2 \mathrm{~nm}$, while Phage S2 had a capsid size of $85 \pm 3 \mathrm{~nm}$ in diameter and a tail length of $136 \pm 3 \mathrm{~nm}$ (Figure 1a,b). 
(a)

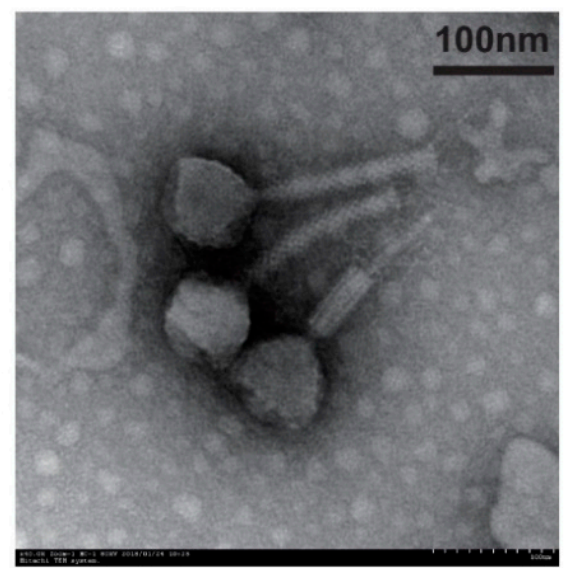

(b)

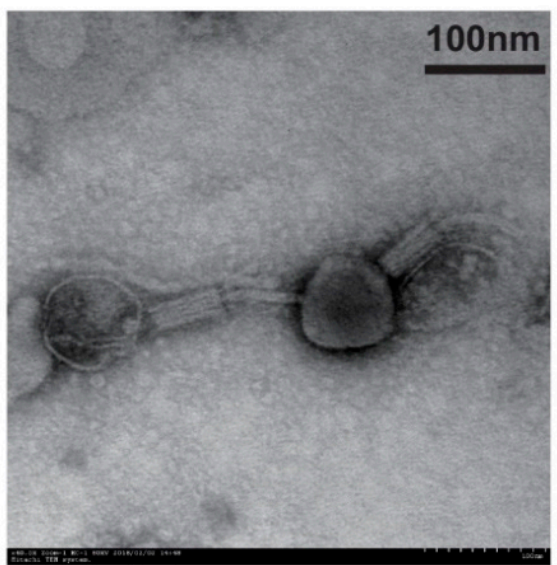

Figure 1. Transmission electron microscopy images of phages (a) vB_PaeM_SCUT-S1 and (b) vB_PaeM_SCUT-S2 negatively stained by $2 \%$ phosphotungstic acid.

\subsection{Basic Characteristics of the Genomes}

After performing the genome sequencing and data processing, high-quality, 578 and $424 \mathrm{Mbp}$ sequences were obtained for Phages S1 and S2, and the average genome coverage was about $\sim 8700$ and $\sim 4500$, respectively. After performing the assembly and manually refinement, we obtained the complete genomes of the two phages. For Phage S1, the genome had a size of 66,089 bp and a G + $\mathrm{C}$ content of $55.43 \%$. The genome termini were identified as circularly permuted by assessing the sequence coverage using PhageTerm. The predicted Pac site was located in an AT-rich region, which could be a replication origin (Figure 2). The genome was tightly organized, and the coding regions were about $93 \%$ of the whole genome with 94 predicted ORFs (Figure 2 and Table S2). None of the tRNA prediction tools used was able to identify any tRNA genes, indicating that Phage S1 is likely to exploit the host tRNA machinery for its protein synthesis. For Phage S2, the complete genome size was 94,434 bp with direct repeats (DRs) of $1189 \mathrm{bp}$ at the ends. There were 197 ORFs identified for Phage S2 (Figure 3 and Table S3). Phage S2 had a much lower G + C content (49.34\%) than that of the host strain PAO1 (66.3\%), which was indicative of differences in the codon usage between the phage and its host. Accordingly, a tRNA cluster of 11 tRNA genes was predicted (Figure 3).

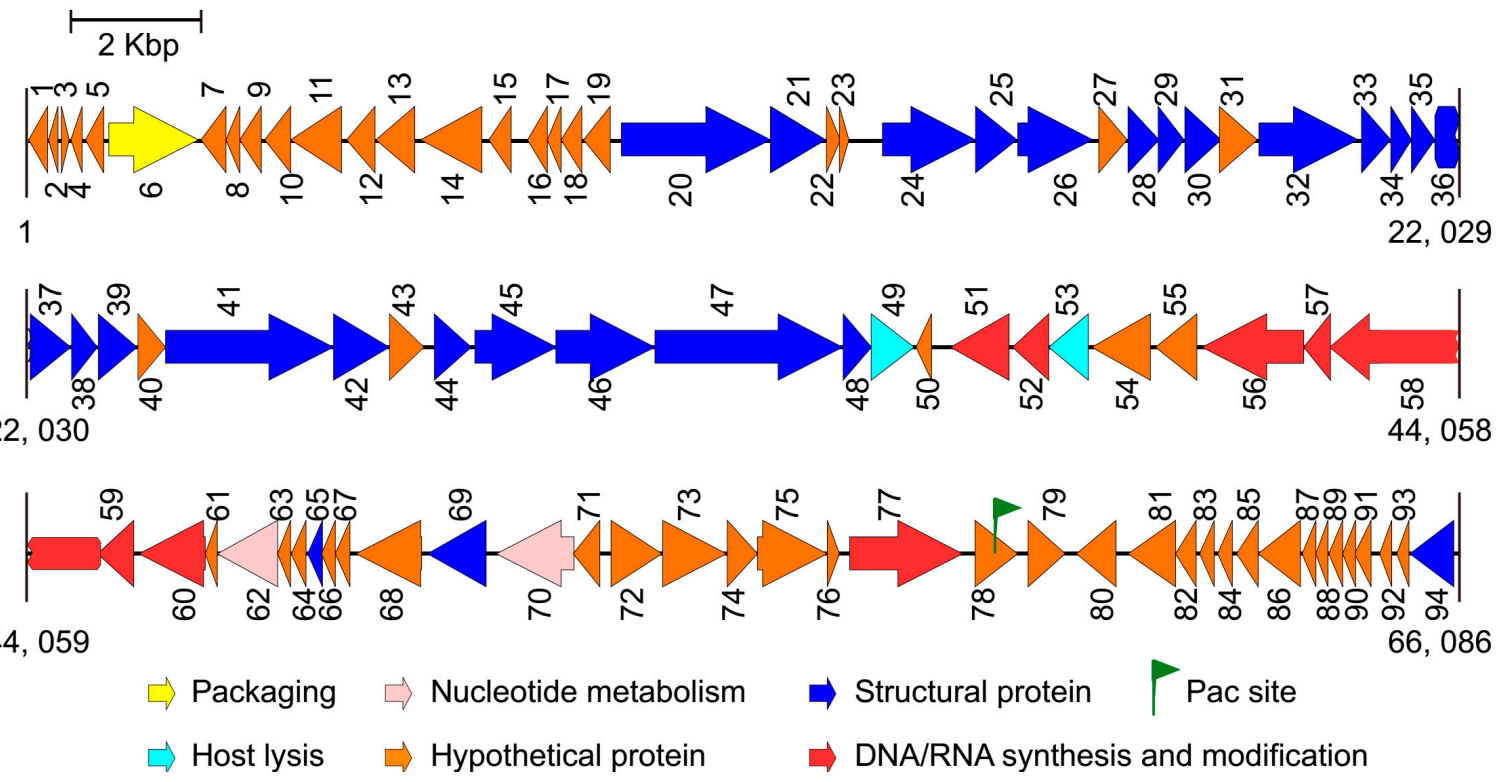

Figure 2. Genome map of phage vB_PaeM_SCUT-S1. The arrows indicate the predicted open reading frames, and the different colors indicate the diverse functions of the coded proteins. 

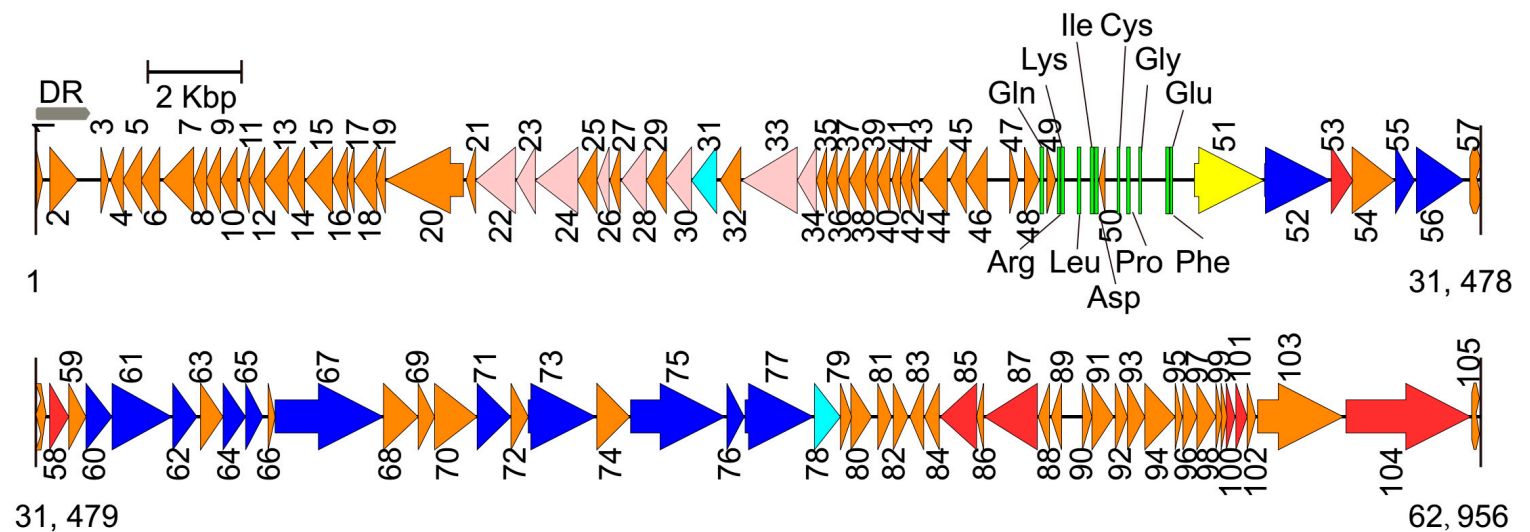

31,479

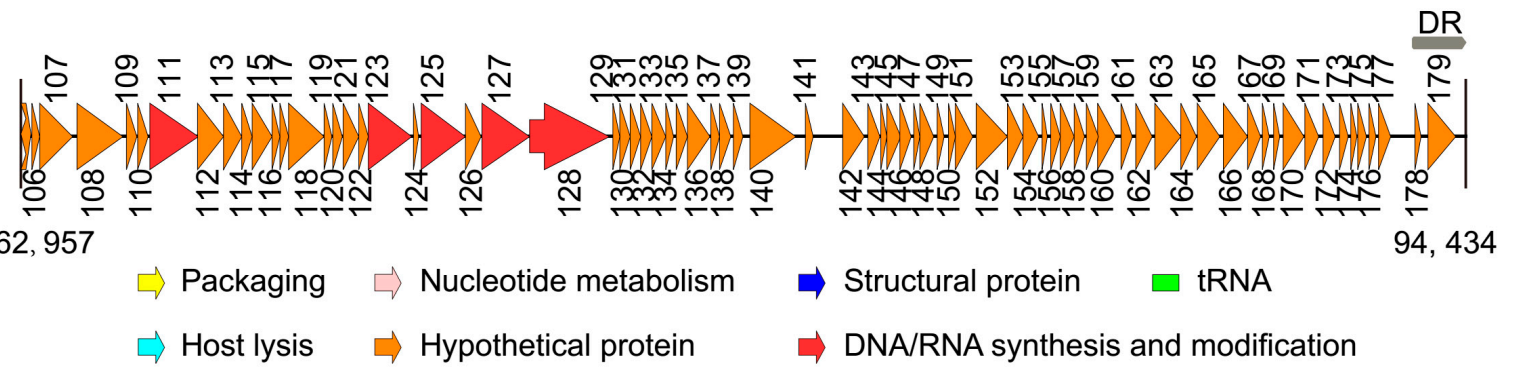

Figure 3. Genome map of phage vB_PaeM_SCUT-S2. The arrows indicate the predicted open reading frames, and the different colors indicate the diverse functions of the coded proteins. DR: direct repeat.

The proteins identified for the two phages could be categorized into five functional classes: nucleotide metabolism and DNA replication (including DNA repair and modification), virion structure (including capsid and tail morphogenesis), DNA packaging, host lysis, and hypothetical proteins (Figures 2 and 3; Tables S2 and S3). The structural protein genes were well clustered, and the nucleotide metabolism and replication-related genes neighbored each other. In addition, three and five clusters of unknown function were annotated for Phages S1 and S2 (i.e., ORF7-19, ORF71-76, and ORF78-93 for Phage S1 and ORF1-21, ORF34-49, ORF79-99, ORF105-121, and ORF129-179 for Phage S2), respectively. No integrase, excisionase, and repressor genes, which are considered indicative of potential for a lysogenic cycle, were found in the two genomes, supporting the conclusion that both S1 and S2 are lytic phages.

\subsection{Comparative Genome Analysis}

The BLASTN results indicated that Phages S1 and S2 were homologous to the viruses of genera Pbunavirus and Pakpunavirus, with the nucleotide similarity to congeneric phages varying from $68.56-94.00 \%$ and $94.97-97.99 \%$, respectively. Based on these results, we compared the amino acid identity of the two phages to their five most similar phages by BLASTP analysis. Phage $\mathrm{S} 1$ harbored two or more unique ORFs, and Phage S2 had six or more unique ORFs (Table S4). There were 50 and 22 complete genome sequences for genus Pbunavirus (taxid:1198980) and Pakpunavirus (taxid:1921407) in the Genbank database (as to December 2018), respectively. Thus, the intra-genus phylogenetic location was explored at a genomic scale. For Phage S1, no phages were found at the same evolutionary level. Phage S1 had the highest homology with phage vB_Pae_PS44 (KM434184.1) isolated in Poland and phage LBL3 (FM201281.1) isolated in Belgium, and was more distantly related to Burkholderia ambifaria phage BcepF1 (EF153632.1), isolated in the USA, and Escherichia phage FEC19 (MH816966.1), isolated in China (Figure 4). For the phages of Pakpunavirus, two main distant clades were clustered, the smallest of which consisted of five phages. To better illustrate the phylogeny of Phage S2, the members of the largest clade were selected and used to construct the maximum likelihood tree. Phage S2 was located at a distinct branch, with a close relationship to phage C11 (KT804923.1) isolated in China and distant to the other phages, which is indicative of the low homology of Phage S2 to the other 
Pakpunavirus (Figure 5). Since the comparative genome analysis indicated that Phages S1 and S2 are new members of the genera Pbunavirus and Pakpunavirus, respectively, the phylogenetic relationships among Pseudomonas phages of the Myoviridae family were explored based on the terminase large subunit (Figure S3). Most phages clustered in five groups, especially the Pbunavirus group (Green) and Pakpunavirus group (Brown) (Figure S3). Pbunaviruses showed a distant relationship to the other groups, separated by some phages in the scattered clades (Figure S3).

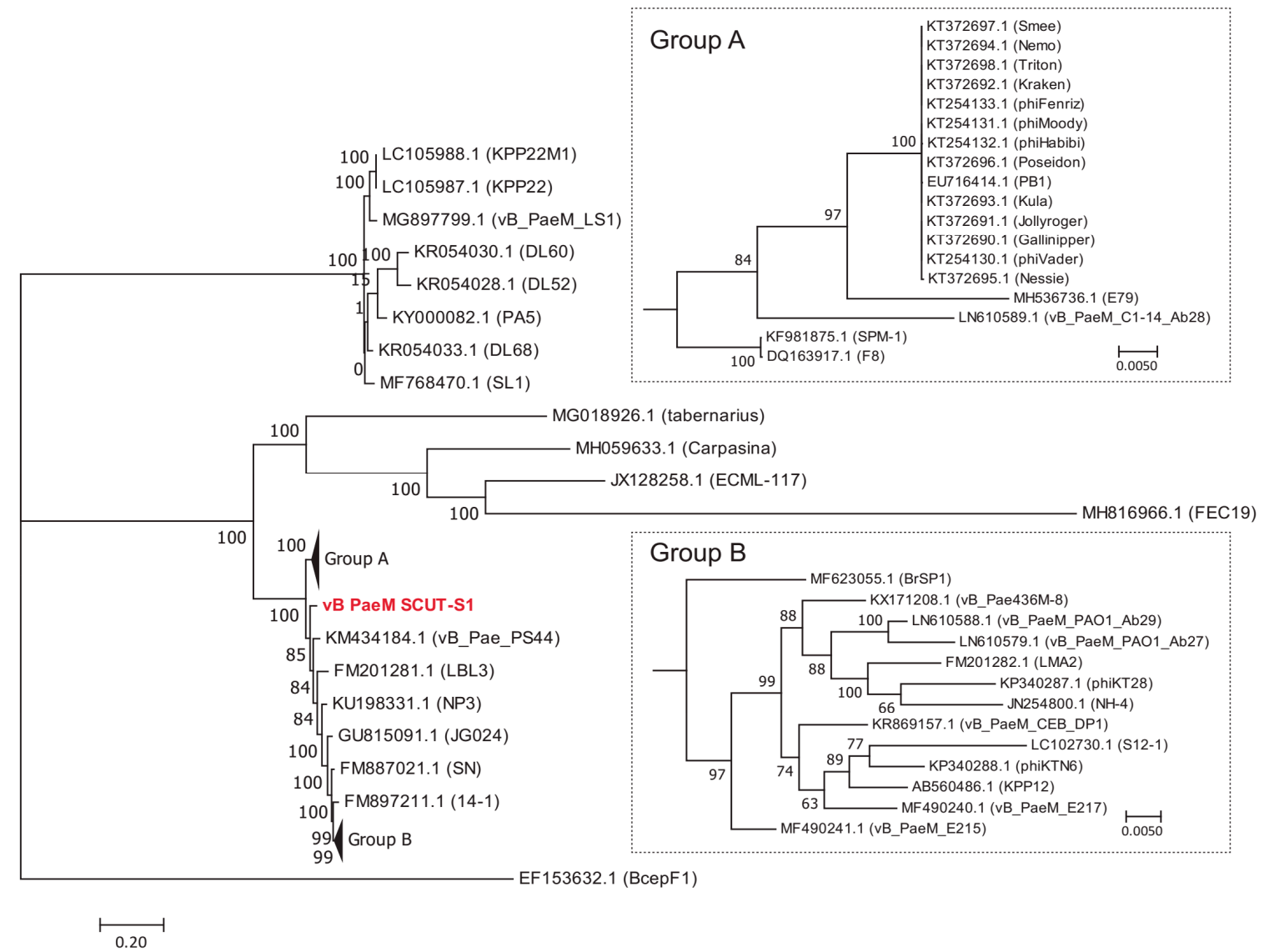

Figure 4. Maximum likelihood tree showing the phylogenetic relationships among phages of genus Pbunavirus. The whole genome sequences were aligned by MAFFT [37], and the tree was visualized by MEGA 7 [40]. The value at the nodes indicated the bootstrap support scores as calculated using 1000 replicates. Phage vB_PaeM_SCUT-S1 was colored red. 


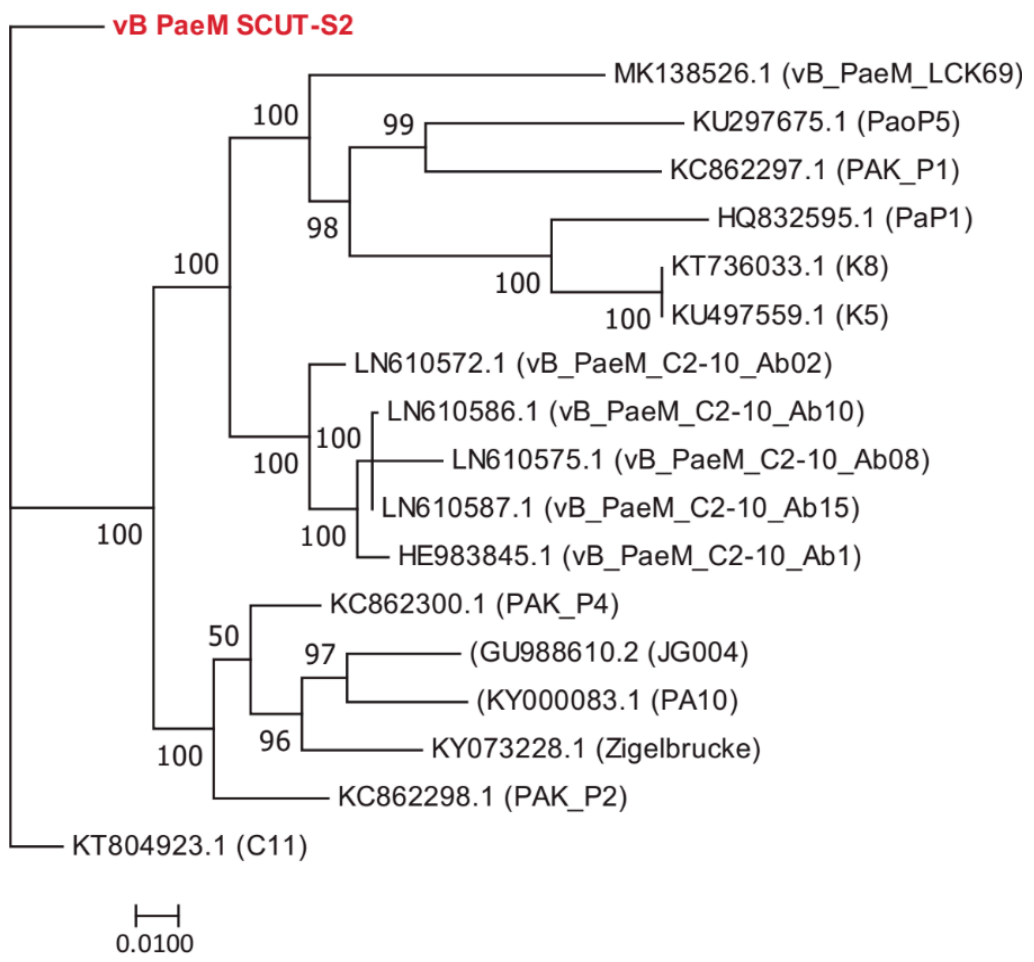

Figure 5. Maximum likelihood tree showing the phylogenetic relationships among phages of genus Pakpunavirus. The whole genome sequences were aligned by MAFFT [37] and the tree was visualized by MEGA 7 [40]. The value at the nodes indicated the bootstrap support scores as calculated using 1000 replicates. Phage vB_PaeM_SCUT-S2 was colored red.

\subsection{Structural Proteins of the Two Phages}

To better understand the functions of the annotated genes, we performed a proteomic analysis of the two phages. After the genomic DNAs of the purified phage particles were released by $\mathrm{LiCl}$, the phages proteins were separated by SDS-PAGE on a $12 \%$ gel. The protein profiles of the two phages were different due to their distinct genomes (Figure S2). For Phage S1, at least 16 protein bands were detected with a molecular mass ranging from 12 to $100 \mathrm{kDa}$ (Figure S2a). About 14 protein bands within the range from 14 to $90 \mathrm{kDa}$ were detected for Phage S2 (Figure S2b). In order to identify low abundance proteins that might not be detected by Coomassie blue staining, the whole lane of the gels was cut and analyzed by nanoLC-MS/MS instead of each stained band. Using the predicted ORFs as the searching database, 31 proteins with at least two detected peptides were identified for the two phages (Tables 1 and 2). For most of the identified proteins (i.e., 27/31 for Phage S1 and 20/31 for Phage S2), the sequence coverage was above $20 \%$ (Tables 1 and 2), which indicated the high confidence of the peptides. We speculated that ORF22, ORF27, ORF31, and ORF54 of Phage S1, and ORF57, ORF59, ORF63, ORF68, ORF69, ORF70, ORF72, ORF74, and ORF80 of Phage S2 could be virion structural proteins, based on the vicinity of their genes to genes coding for structural proteins. For ORF11, ORF72, and ORF84 of Phage S1, and ORF14, ORF80, and ORF140 of Phage S2, no function could be assigned. 
Table 1. Genes encoding virion proteins in vB_PaeM_SCUT-S1 identified by mass spectrometry.

\begin{tabular}{lccccc}
\hline No. & Predicted Function & Gene No. & $\begin{array}{c}\text { Mol. Mass } \\
\text { (kDa) }\end{array}$ & $\begin{array}{c}\text { No. of } \\
\text { Peptides }\end{array}$ & Coverage \\
\hline 1 & putative tail protein containing & ORF41 & 94.39 & 72 & $81 \%$ \\
2 & transglycosylase & ORF47 & 103.16 & 44 & $63 \%$ \\
3 & putative tail fiber protein & ORF20 & 84.53 & 44 & $59 \%$ \\
4 & putative minor head protein & ORF46 & 54.81 & 23 & $60 \%$ \\
5 & putative major structural protein & ORF26 & 41.59 & 20 & $49 \%$ \\
6 & putative structural protein & ORF32 & 53.82 & 19 & $47 \%$ \\
7 & putative minor head protein & ORF21 & 31.72 & 16 & $56 \%$ \\
8 & putative structural protein & ORF24 & 52.10 & 14 & $38 \%$ \\
9 & putative tail fiber protein & ORF33 & 15.91 & 12 & $70 \%$ \\
10 & putative structural protein & ORF42 & 32.60 & 12 & $58 \%$ \\
11 & putative structural protein & ORF31 & 21.48 & 12 & $77 \%$ \\
12 & putative baseplate protein & ORF45 & 43.51 & 11 & $41 \%$ \\
13 & putative endolysin & ORF49 & 24.35 & 11 & $48 \%$ \\
14 & putative structural protein & ORF25 & 21.57 & 9 & $59 \%$ \\
15 & putative structural protein & ORF38 & 19.94 & 9 & $60 \%$ \\
16 & putative structural protein & ORF54 & 32.21 & 8 & $25 \%$ \\
17 & putative structural protein & ORF37 & 17.80 & 7 & $67 \%$ \\
18 & putative structural protein & ORF28 & 16.96 & 7 & $30 \%$ \\
19 & putative structural protein & ORF22 & 7.46 & 7 & $77 \%$ \\
20 & putative tail fiber protein & ORF39 & 21.70 & 6 & $44 \%$ \\
21 & putative structural protein & ORF36 & 14.46 & 6 & $50 \%$ \\
22 & putative structural protein & ORF35 & 12.74 & 5 & $29 \%$ \\
23 & unknown function protein & ORF84 & 8.61 & 4 & $47 \%$ \\
24 & putative holin & ORF53 & 21.13 & 4 & $25 \%$ \\
25 & putative structural protein & ORF27 & 16.37 & 4 & $22 \%$ \\
26 & putative DNA helicase & ORF56 & 59.43 & 4 & $7 \%$ \\
27 & putative structural protein & ORF34 & 12.36 & 3 & $42 \%$ \\
28 & putative ATP-dependent exonuclease V & ORF70 & 45.54 & 3 & $7 \%$ \\
29 & putative baseplate protein & ORF44 & 24.17 & 3 & $13 \%$ \\
31 & unknown function protein & ORF72 & 29.47 & 3 & $10 \%$ \\
\hline & unknown function protein & ORF11 & 15.52 & 2 & $21 \%$ \\
\hline
\end{tabular}

The first step of bacteria elimination by phages is their successful invasion into the host cells $[46,47]$. During this process, the tail fiber proteins are believed to play an important role in host recognition, and a single amino acid mutation can change the host specificity and give the phage the capacity of infecting different species of bacteria $[48,49]$. Thus, we compared the predicted tail fiber proteins of the five closest phages based on the terminase large subunit (Figures 4 and 5). For the tail fiber proteins of Phage S1 and related phages, ORF33 presented only few amino acid differences and ORF47 showed some variations at the C-terminus (Figure S4a). In the case of Phage S2 and related phages, ORF75 presented low identity at the C-terminus and ORF77 showed some amino acid mutations (Figure S4b). Interestingly, several proteins involved in nucleotide metabolism and DNA modification were detected in the phages particles, such as putative DNA helicase (ORF56 of S1), putative RNA polymerase (ORF58 of S2), putative ATP-dependent exonuclease V (ORF70 of S1), putative ribonucleoside-diphosphate reductase alpha and beta subunits (ORF127 and ORF128 of S2), putative 3'-phosphatase (ORF123 of S2), putative nictotinate phosphoribosyltransferase (ORF20 of S2), and putative methyltransferase (ORF53 of S2) (Tables 1 and 2), which indicate a potential role of these proteins in the phage infection mechanism. 
Table 2. Genes encoding virion proteins in vB_PaeM_SCUT-S2 identified by mass spectrometry.

\begin{tabular}{|c|c|c|c|c|c|}
\hline No. & Predicted Function & Gene No. & $\begin{array}{l}\text { Mol. Mass } \\
(\text { kDa) }\end{array}$ & $\begin{array}{c}\text { No. of } \\
\text { Peptides }\end{array}$ & Coverage \\
\hline 1 & putative tape measure protein & ORF67 & 85.86 & 55 & $66 \%$ \\
\hline 2 & putative structural protein & ORF52 & 54.49 & 38 & $77 \%$ \\
\hline 3 & putative structural protein & ORF61 & 46.35 & 31 & $51 \%$ \\
\hline 4 & major capsid protein & ORF56 & 39.41 & 30 & $72 \%$ \\
\hline 5 & putative tail fiber protein & ORF75 & 71.97 & 29 & $69 \%$ \\
\hline 6 & putative tail fiber protein & ORF77 & 53.15 & 23 & $58 \%$ \\
\hline 7 & putative baseplate component & ORF73 & 52.37 & 17 & $36 \%$ \\
\hline 8 & putative structural protein & ORF74 & 26.64 & 17 & $80 \%$ \\
\hline 9 & putative structural protein & ORF55 & 14.85 & 14 & $90 \%$ \\
\hline 10 & putative baseplate protein & ORF71 & 26.84 & 11 & $53 \%$ \\
\hline 11 & putative structural protein & ORF60 & 21.27 & 10 & $43 \%$ \\
\hline 12 & putative structural protein & ORF70 & 34.17 & 10 & $35 \%$ \\
\hline 13 & putative structural protein & ORF68 & 28.60 & 10 & $49 \%$ \\
\hline 14 & putative structural protein & ORF57 & 18.24 & 9 & $40 \%$ \\
\hline 15 & putative structural protein & ORF62 & 18.95 & 8 & $55 \%$ \\
\hline 16 & putative structural protein & ORF63 & 18.29 & 8 & $40 \%$ \\
\hline 17 & putative structural protein & ORF72 & 14.07 & 7 & $32 \%$ \\
\hline 18 & putative structural protein & ORF59 & 14.46 & 7 & $73 \%$ \\
\hline 19 & unknown function protein & ORF108 & 37.10 & 6 & $17 \%$ \\
\hline 20 & putative RNA polymerase & ORF58 & 15.51 & 5 & $15 \%$ \\
\hline 21 & putative structural protein & ORF80 & 16.06 & 4 & $32 \%$ \\
\hline 22 & putative endolysin & ORF78 & 20.89 & 4 & $20 \%$ \\
\hline 23 & $\begin{array}{l}\text { putative ribonucleoside-diphosphate } \\
\text { reductase alpha chain }\end{array}$ & ORF128 & 67.42 & 4 & $6 \%$ \\
\hline 24 & $\begin{array}{l}\text { putative ribonucleoside-diphosphate } \\
\text { reductase beta subunit }\end{array}$ & ORF127 & 40.62 & 4 & $8 \%$ \\
\hline 25 & putative $3^{\prime}$-phosphatase & ORF123 & 35.43 & 3 & $9 \%$ \\
\hline 26 & $\begin{array}{c}\text { putative nictotinate } \\
\text { phosphoribosyltransferase }\end{array}$ & ORF20 & 63.05 & 3 & $5 \%$ \\
\hline 27 & unknown function protein & ORF14 & 14.86 & 3 & $6 \%$ \\
\hline 28 & putative structural protein & ORF64 & 17.75 & 2 & $12 \%$ \\
\hline 29 & putative methyltransferase & ORF53 & 17.27 & 2 & $14 \%$ \\
\hline 30 & putative structural protein & ORF69 & 13.98 & 2 & $20 \%$ \\
\hline 31 & unknown function protein & ORF140 & 37.78 & 2 & $4 \%$ \\
\hline
\end{tabular}

\subsection{Stability Analysis}

After the characterization at genomic and proteomic level, the physiological properties of Phages $\mathrm{S} 1$ and S2, in terms of $\mathrm{pH}$ and temperature stability, were investigated. Phage S1 was more robust to $\mathrm{pH}$ changes than Phage S2 was. Their infectivity both remained almost intact when exposed for $1 \mathrm{~h}$ to a pH ranging from 4 to 10 (Figure $6 \mathrm{a}, \mathrm{b}$ ). However, the performance changed when exposed to the cruel $\mathrm{pH}$ conditions. The infectivity of Phage S1 slightly decreased at $\mathrm{pH} 3$ and $\mathrm{pH} 11$ (Figure 6a), while that of Phage S2 decreased significantly at $\mathrm{pH} 3$ and nearly lost at $\mathrm{pH} 11$ (Figure 6b). The two phages were both inactivated when exposed to $\mathrm{pH} 12$ (Figure 6a,b). Regarding the temperature stability, the two phages also showed different properties. The infectivity of Phage S1 decreased gradually upon increasing the temperature when exposed for $1 \mathrm{~h}$ to temperatures ranging from 30 to $60^{\circ} \mathrm{C}$, dropped significantly at $70{ }^{\circ} \mathrm{C}$, and was completely lost at $80^{\circ} \mathrm{C}$ (Figure 6c). Conversely, the infectivity of Phage S2 showed a slight decrease upon increasing the temperature up to $60^{\circ} \mathrm{C}$ but was completely lost at $70{ }^{\circ} \mathrm{C}$ or above (Figure $6 \mathrm{~d}$ ). The different response of the two phages to the temperature could result from their distinct capsid proteins or structures. 
(a)

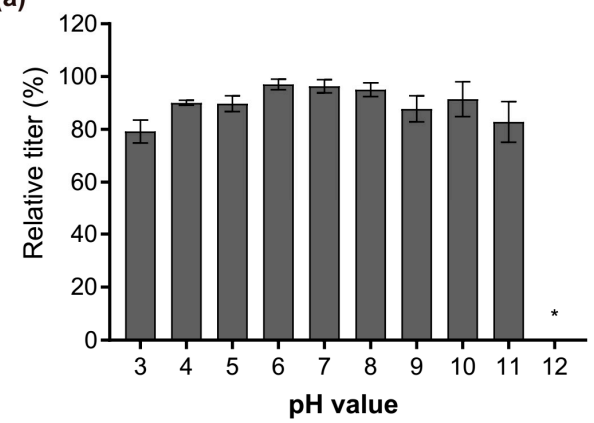

(c)

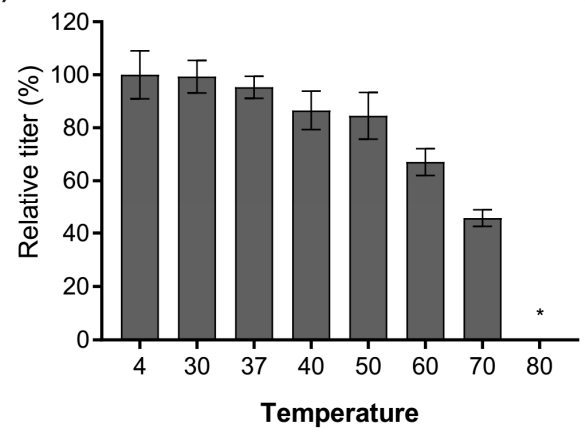

(b)

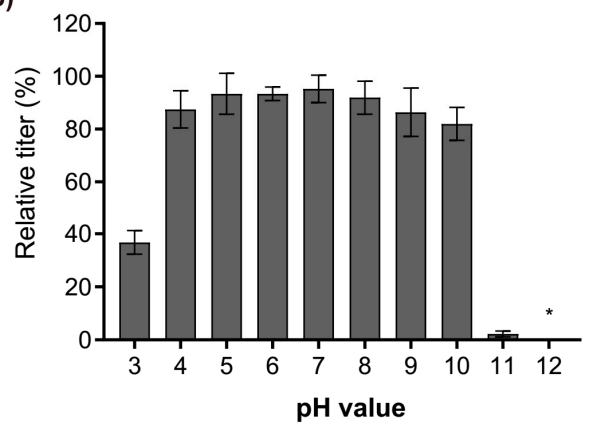

(d)

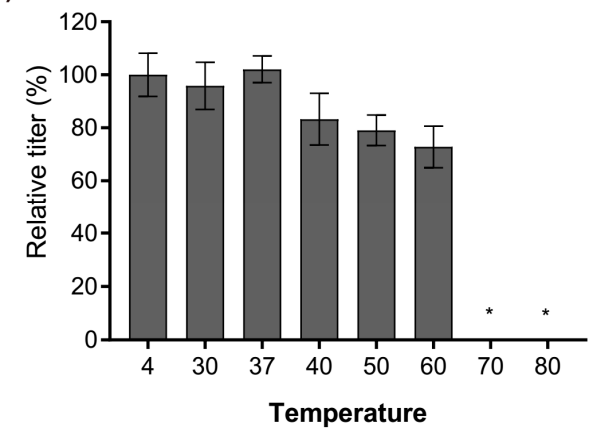

Figure 6. Relative amount of infectious phage particles after different treatments. (a) vB_PaeM_SCUT-S1 and (b) vB_PaeM_SCUT-S2 incubated for $1 \mathrm{~h}$ at different pH levels; (c) vB_PaeM_SCUT-S1 and (d) vB_PaeM_SCUT-S2 incubated for $1 \mathrm{~h}$ at different temperatures. ${ }^{*}$ No plaques were detected at $\mathrm{pH} 12$ for either Phages S1 and S2 (a,b), at $80{ }^{\circ} \mathrm{C}$ for Phage S1 (c) and at $70{ }^{\circ} \mathrm{C}$ or $80^{\circ} \mathrm{C}$ for Phage S2 (d), indicating that the phages were completely inactive in these conditions. Three independent experiments were performed.

\subsection{Growth Characteristics and Lysis Kinetics}

The one-step growth curve analysis revealed that Phages S1 and S2 had distinctive life cycles (Figure $7 \mathrm{a}, \mathrm{b}$ ). Phage $\mathrm{S} 1$ had a latent period of $40 \mathrm{~min}$ and a rise period of $10 \mathrm{~min}$, and generated about 134 virion progenies per infected cell (Figure 7a). Phage S2 had a shorter latent period and a prolonged rise period, both being about $25 \mathrm{~min}$, and the average burst size was much lower (i.e., 40 progenies per infected cell) than that of Phage S1 (Figure 7b). These differences in growth kinetics can result in different host lysis efficiency.

(a)

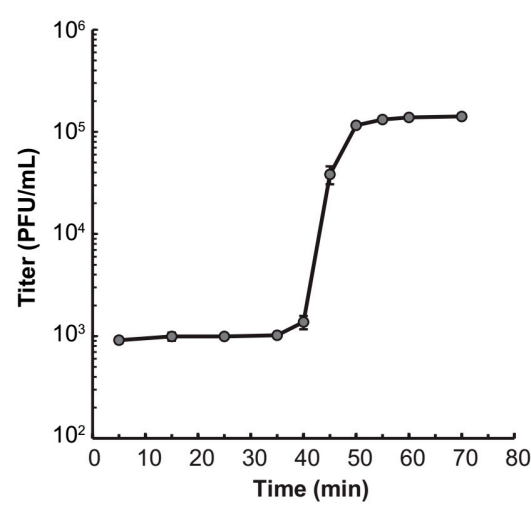

(b)

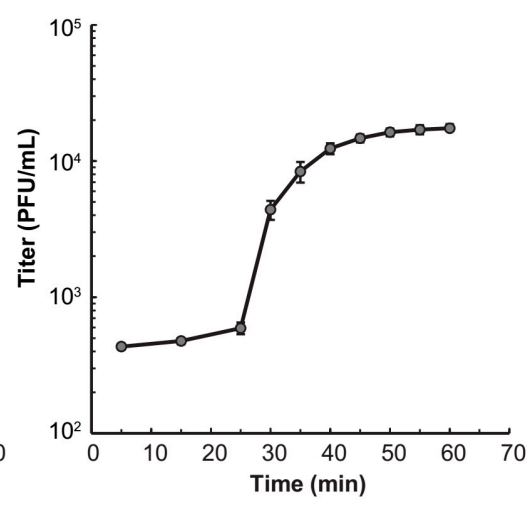

Figure 7. One step growth curve of (a) vB_PaeM_SCUT-S1 and (b) vB_PaeM_SCUT-S1. Data are presented as the mean ( \pm standard deviations) titers measured at the indicated infection time obtained from three independent experiments. 
The effect of S1 and S2 against P. aeruginosa PAO1 planktonic cultures were determined by using the phages alone or in combination. Phages S1 and S2 efficiently inhibited the growth of the host bacteria at the exponential phase. The number of phages had a great influence on bacterial growth in the early stage, and at the highest titer (i.e., MOI $=100$ ) the phages could kill the host cells directly without needing a latent period to produce further virions (Figure 8a,b). As the growth time elapsed, this advantage of higher phage titers gradually disappeared. The bacterial growth was totally inhibited by Phage S2 after $3.5 \mathrm{~h}$ for the different treatments, including the lowest $\mathrm{MOI}=0.01$ (Figure $8 \mathrm{~b}$ ). The inhibitory effect of Phage S1 was slightly lower than Phage S2 (Figure 8a). The host lysis became inefficient after $12 \mathrm{~h}$ of culture, and the higher the MOI used at the beginning, the higher the bacteria grown at $20 \mathrm{~h}$ (Figure 8a,b), which suggested the emergence of phage-insensitive or phage-resistant strains. This phenomenon was not alleviated by using the two phages in combination (Figure 8c). The lysis curve observed using a 1:1 mixture of Phages S1 and S2 was very similar to that obtained using Phage S2 alone, indicating that the lysis induced by Phage S1 was nearly covered by that of Phage S2.

(a)

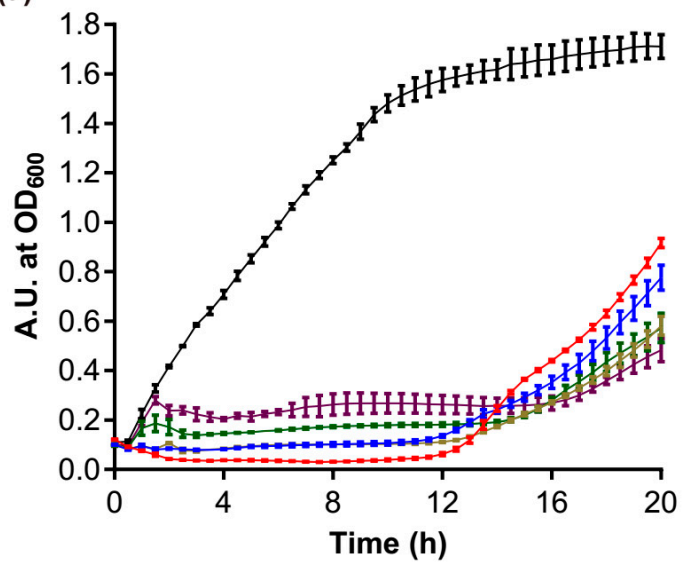

(c)

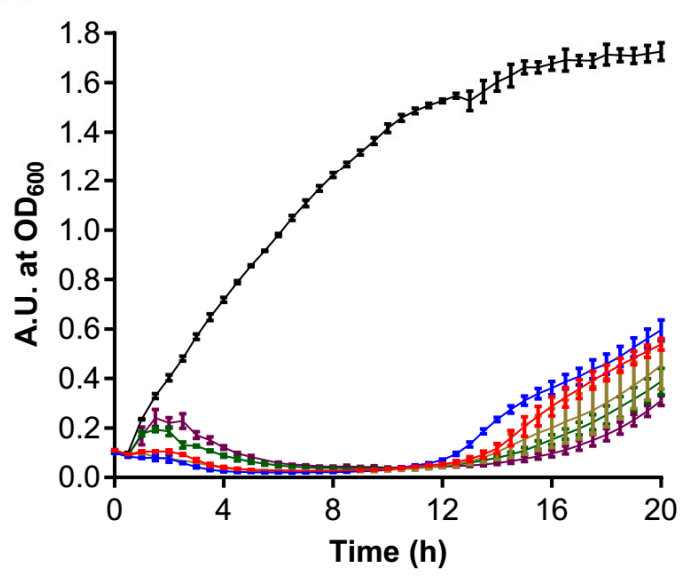

(b)

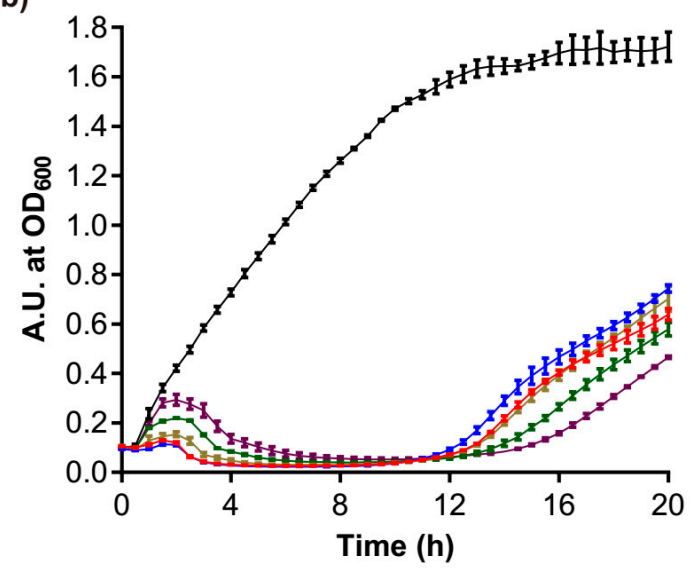

- $\mathrm{MOI}=0$
- $\mathrm{MOI}=100$
- $\mathrm{MOI}=10$
- $\mathrm{MOI}=1$
- $\mathrm{MOI}=0.1$
$-\mathrm{MOI}=0.01$

Figure 8. Growth curves of PAO1 strains infected with different phages. (a) vB_PaeM_SCUT-S1 of different MOIs; (b) vB_PaeM_SCUT-S2 of different MOIs; (c) vB_PaeM_SCUT-S1 and vB_PaeM_SCUT-S2 were combined in a 1:1 ratio to the indicated final MOIs.

\subsection{Biofilm Eradication}

We first tested whether the phages could prevent the biofilm formation based on the biofilm biomass, which was tested by CV staining. The results showed that the phages alone or in combination could effectively inhibit the biofilm growth upon incubation for 4, 8, and $24 \mathrm{~h}$ (Figure S5). Next, the biofilm-degradation capacity of Phages S1 and S2 was evaluated by investigating two complementary 
biofilm properties: the biofilm biomass (tested by $\mathrm{CV}$ staining) and the cell metabolic activity (tested by XTT assay) (Figure 9). When the 24-h-grown PAO1 biofilms were treated with the phages for different time periods $(4,8$, and $24 \mathrm{~h})$, the biofilm was effectively eradicated by either phage used alone as well as by the combination of the two phages (Figure 9). The biomass of the biofilm was reduced more effectively by prolonged treatment. The relative reduction was $5 \%$ at $4 \mathrm{~h}, 10 \%$ at $8 \mathrm{~h}$, and $44 \%$ at $24 \mathrm{~h}$ for Phage S1 and 50\% at $4 \mathrm{~h}, 61 \%$ at $8 \mathrm{~h}$, and $69 \%$ at $24 \mathrm{~h}$ for Phage S2 (Figure $9 \mathrm{a}$ ). The combination of Phages S1 and S2 showed nearly the same reduction observed when using Phage S2 alone (Figure 9a). Regarding the cell metabolic activity, the $8 \mathrm{~h}$ treatment provided the most effective inhibition (i.e., 79\% for Phage S1 and 97\% for both Phage S2 and the combination of Phages S1 and S2, Figure 9b), while upon $24 \mathrm{~h}$ treatment, a significant recovery of metabolic activity was observed (Figure 9b). The observed biofilm metabolic activity was more consistent with the measured lysis kinetics than the biofilm biomass (see paragraph 3.6). Overall, Phage S2 showed a better performance on growth inhibition and biofilm reduction than Phage S1, and the combination of Phages S1 and S2 did not show an obvious synergistic effect in either planktonic cells or biofilm eradication.
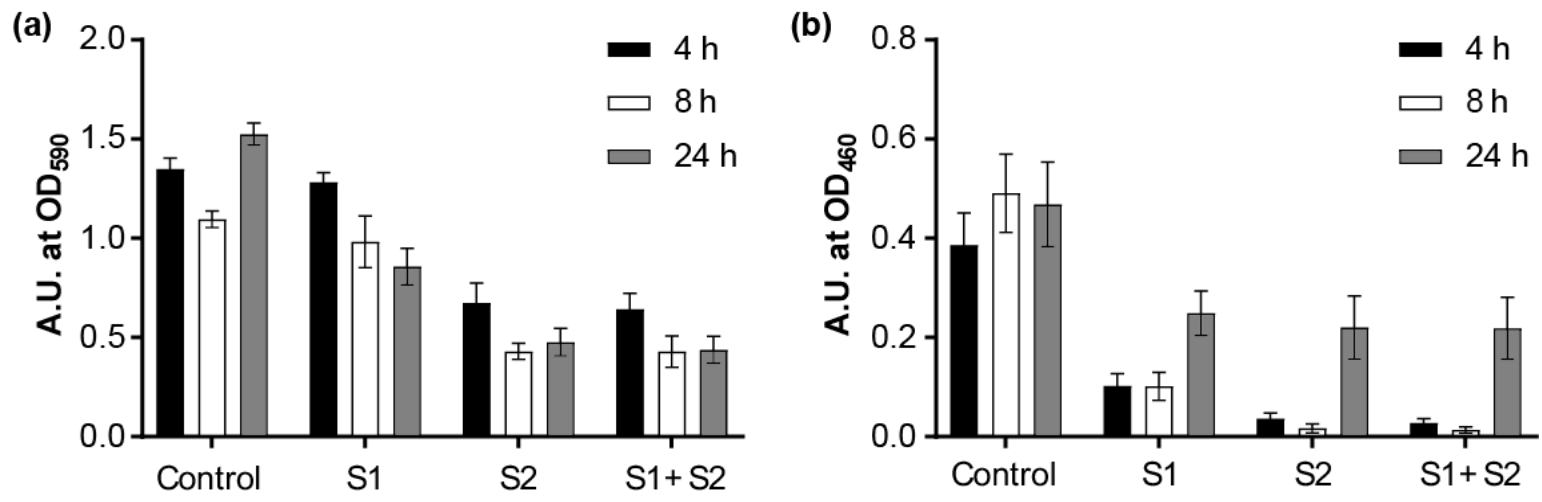

Figure 9. Effect of phage treatment on 24-h-grown biofilms. (a) Biomass evaluation by CV staining; (b) metabolic activity evaluation by XTT assay. Control: without any phages; S1: treated with $10^{8}$ pfu of phage vB_PaeM_SCUT-S1; S2: treated with $10^{8}$ pfu phage vB_PaeM_SCUT-S2; S1 + S2: treated with a mixture of vB_PaeM_SCUT-S1 and vB_PaeM_SCUT-S2 $\left(0.5 \times 10^{8} \mathrm{pfu}\right.$ of each phage). The different treatment duration is indicated by different bar colors.

\section{Discussion}

The identification and characterization of novel phages can enhance our understanding of phage biology. Phages S1 and S2, which were assigned to the Myoviridae family, have genome sizes of $66.1 \mathrm{~kb}$ and $94.4 \mathrm{~kb}$ encoding 94 and 179 putative proteins, respectively. Both phages showed genetic mosaicism, a typical feature of tailed phages [50], with several functional modules clustered throughout their genomes (Figures 2 and 3). In addition to a number of clustered genes coding for proteins with predictable function, several ORFs could only be annotated as coding for proteins with unknown function (Tables S2 and S3), a common problem in phage studies [51]. Based on our proteomic analysis, 23 and 21 ORFs were identified as structural protein coding genes for Phages S1 and S2, respectively (Tables 1 and 2), a result that contributes to the enrichment of phage proteome collection. Although Phages S1 and S2 were isolated from the same location, they belonged to two different genera, Pbunavirus and Pakpunavirus, respectively. Based on the phylogenetic analysis, they were found to be distantly related to each other (Figure S3), suggesting that the two phages evolved independently and might have different roles in regulating bacterial communities. This is consistent with a recent study in which several phages where isolated from a single environmental source [52]. Interestingly, Phage S2 presented a dominant advantage over Phage S1 in infecting PAO1 strain and in reducing its biofilm, which inspires for a better exploration of the relationships between the other phages in the genera Pbunavirus and Pakpunavirus. 
The two phages could be suitable candidates to be further developed for phage therapy. In fact, Phages S1 and S2 are virulent phages with a conventional genome size and no genes coding for toxins, virulence factors, or lysogeny-related proteins were discovered by genome annotation and proteomic analysis (Figures 2 and 3, Tables 1 and 2 and Tables S2 and S3), in contrast to lysogenic phages, which are not recommended for therapy [53]. The infectivity of the phages remained stable in a temperature range of $4-37^{\circ} \mathrm{C}$ and a $\mathrm{pH}$ range of 4-10 (Figure 6), indicating that they could be stored at room temperature and the activity could be maintained in a human physiological condition. Furthermore, they inhibited the growth of planktonic cells effectively alone or together at a low MOI for a $12 \mathrm{~h}$ treatment (Figure 8) and had good performances on preventing the biofilm formation (Figure S5) and eradicating biofilms (Figure 9). However, particular attention should be paid to the potential development of phage resistance in clinical settings since the bacterial growth could be partially recovered with a $24 \mathrm{~h}$ treatment in vitro (Figures 8 and 9). Although the development of bacterial resistance considered inevitable in phage therapy, it is believed to occur less infrequently in vivo than in vitro [54]. In addition, phage adaptation or training performed by in vitro procedures could be utilized to solve this problem [54,55]. For example, the short-term antagonistic evolution of the P. aeruginosa strain PAO1 and the Pbunaviruses phage KPP22 resulted in the formation of KPP22 mutants with recovered infectivity towards phage-resistant PAO1 clones [56].

Members of genera Pbunavirus and Pakpunavirus have been studied for their suitability as therapeutics, and several phages have already been proved to be effective in controlling P. aeruginosa MDR infections in animal models [57-62]. For example, Pbunaviruses $\Phi \mathrm{NH}-4$ could effectively clear the Pseudomonas infection of murine lungs in $6 \mathrm{~h}$ [59], and a cocktail of three Pbunaviruses DL52, DL60, DL68 and other three Podoviridae phages could prolong survival of Galleria mellonella infected by clinical strains of P. aeruginosa [60]. Pakpunavirus PAK_P1 was effective in treating acute lung infection in a mouse model [61] and six closely related Pakpunavirus phages gave high survival rates, between 75 and $100 \%$, with a 13-day treatment in a mouse lung infection model [62]. Phages S1 and S2 harbored distinctive fiber proteins (Figure S4) and might give rise to unique host recognition ranges [48,49]. Consequently, Phages S1 and S2 can have a host range different from that of previously reported phages $[21,63,64]$ (e.g., both phages could infect 6/7 host P. aeruginosa strains in our study (Table S1)), which makes them potential candidates for their inclusion in phage therapy cocktails. Further research will study their efficacy in controlling clinical P. aeruginosa MDR infections and confirm the safety of the two phages as therapeutic tools.

Supplementary Materials: The following are available online at http://www.mdpi.com/1999-4915/11/4/318/s1. Figure S1: Plaques formed by phage vB_PaeM_SCUT-S1 (a) and vB_PaeM_SCUT-S2 (b) infecting P. aeruginosa PAO1. Figure S2: Identification of the structural proteins by SDS-PAGE analysis. Figure S3: Neighbor-joining tree showing the phylogenetic relationships among Pseudomonas phages of Myoviridae family. Figure S4: The comparison of the tail fiber proteins of phage vB_PaeM_SCUT-S1 (a) and vB_PaeM_SCUT-S2 (b) to the five most closely related phages. Figure S5. The inhibitory effect of phage treatment on biofilm formation based on the biomass tested by CV staining. Table S1: Host range of phage vB_PaeM_SCUT-S1 and vB_PaeM_SCUT-S2. Table S2: The genome annotation of Pseudomonas phage vB_PaeM_SCUT-S1. Table S3: The genome annotation of Pseudomonas phage vB_PaeM_SCUT-S2. Table S4: Amino acid identity between phage vB_PaeM_SCUT-S1 (a) and phage vB_PaeM_SCUT-S2 (b) with five most similar members indicated by BLASTN analysis.

Author Contributions: Conceptualization: T.W. Formal analysis: Y.G., P.C. and T.W. Investigation: Y.G. Project administration: T.W. Supervision: Z.L. Visualization: Y.G. and T.W. Writing—original draft: Y.G. and T.W. Writing-review \& editing: P.C., Z.L. and T.W.

Funding: This study was funded by the National Natural Science Founding of China (Grant No. 31800718), the Doctoral Scientific Research Foundation of China (Grant No. 2017M612649), the National Natural Science Founding of Guangdong province (Grant No. 2018A030310361) and the Fundamental Research Funds for the Central Universities of South China University of Technology (Grant No. x2sw-D2172890, x2sw-D2172900 and x2sw-D2182030).

Acknowledgments: We thank the members of Lin's lab, South China University of Technology, for the helpful discussions and Marco Pistolozzi, South China University of Technology, for revising the manuscript. We thank Ming Li of the Third Military Medical University for generously providing us with the PAO1 strain. 
Conflicts of Interest: The authors declare no conflict of interest. The funders had no role in the design of the study; in the collection, analyses, or interpretation of data; in the writing of the manuscript; or in the decision to publish the results.

\section{References}

1. Boucher, H.W.; Talbot, G.H.; Bradley, J.S.; Edwards, J.E.; Gilbert, D.; Rice, L.B.; Scheld, M.; Spellberg, B.; Bartlett, J. Bad bugs, no drugs: No eskape! An update from the infectious diseases society of america. Clin. Infect. Dis. 2009, 48, 1-12. [CrossRef]

2. Pendleton, J.N.; Gorman, S.P.; Gilmore, B.F. Clinical relevance of the eskape pathogens. Expert Rev. Anti Infect. 2013, 11, 297-308. [CrossRef]

3. Santajit, S.; Indrawattana, N. Mechanisms of antimicrobial resistance in eskape pathogens. Biomed. Res. Int. 2016, 2016, 2475067. [CrossRef]

4. $\quad$ Emerson, J.; Rosenfeld, M.; McNamara, S.; Ramsey, B.; Gibson, R.L. Pseudomonas aeruginosa and other predictors of mortality and morbidity in young children with cystic fibrosis. Pediatric Pulmonol. 2002, 34, 91-100. [CrossRef] [PubMed]

5. Lyczak, J.B.; Cannon, C.L.; Pier, G.B. Establishment of pseudomonas aeruginosa infection: Lessons from a versatile opportunist. Microbes Infect. 2000, 2, 1051-1060. [CrossRef]

6. Mesaros, N.; Nordmann, P.; Plésiat, P.; Roussel-Delvallez, M.; Van Eldere, J.; Glupczynski, Y.; Van Laethem, Y.; Jacobs, F.; Lebecque, P.; Malfroot, A.; et al. Pseudomonas aeruginosa: Resistance and therapeutic options at the turn of the new millennium. Clin. Microbiol. Infect. 2007, 13, 560-578. [CrossRef]

7. Lister, P.D.; Wolter, D.J.; Hanson, N.D. Antibacterial-resistant pseudomonas aeruginosa: Clinical impact and complex regulation of chromosomally encoded resistance mechanisms. Clin. Microbiol. Rev. 2009, 22, 582-610. [CrossRef]

8. Chatterjee, M.; Anju, C.P.; Biswas, L.; Anil Kumar, V.; Gopi Mohan, C.; Biswas, R. Antibiotic resistance in pseudomonas aeruginosa and alternative therapeutic options. Int. J. Med. Microbiol. 2016, 306, 48-58. [CrossRef]

9. Wagner, S.; Sommer, R.; Hinsberger, S.; Lu, C.; Hartmann, R.W.; Empting, M.; Titz, A. Novel strategies for the treatment of pseudomonas aeruginosa infections. J. Med. Chem. 2016, 59, 5929-5969. [CrossRef] [PubMed]

10. Reardon, S. Phage therapy gets revitalized. Nature 2014, 510, 15-16. [CrossRef]

11. Loc-Carrillo, C.; Abedon, S.T. Pros and cons of phage therapy. Bacteriophage 2014, 1, 111-114. [CrossRef]

12. Dublanchet, A.; Fruciano, E. A short history of phage therapy. Med. Et Mal. Infect. 2008, 38, 415-420. [CrossRef]

13. Summers, W.C. Bacteriophage research: Early history. In Bacteriophages: Biology and Applications; CRC Press: Boca Raton, FL, USA, 2005; pp. 5-27.

14. Chan, B.K.; Abedon, S.T.; Loc-Carrillo, C. Phage cocktails and the future of phage therapy. Future Microbiol. 2013, 8, 769-783. [CrossRef]

15. Aziz, R.K.; Ackermann, H.W.; Petty, N.K.; Kropinski, A.M. Essential steps in characterizing bacteriophages: Biology, taxonomy, and genome analysis. Methods Mol. Biol. 2018, 1681, 197-215.

16. McVay, C.S.; Velasquez, M.; Fralick, J.A. Phage therapy of pseudomonas aeruginosa infection in a mouse burn wound model. Antimicrob. Agents Chemother. 2007, 51, 1934-1938. [CrossRef]

17. Kutter, E.; De Vos, D.; Gvasalia, G.; Alavidze, Z.; Gogokhia, L.; Kuhl, S.; Abedon, S. Phage therapy in clinical practice: Treatment of human infections. Curr. Pharm. Biotechnol. 2010, 11, 69-86. [CrossRef]

18. De Smet, J.; Hendrix, H.; Blasdel, B.G.; Danis-Wlodarczyk, K.; Lavigne, R. Pseudomonas predators: Understanding and exploiting phage-host interactions. Nat. Rev. Microbiol. 2017, 15, 517-530. [CrossRef]

19. Weber-Dabrowska, B.; Jonczyk-Matysiak, E.; Zaczek, M.; Lobocka, M.; Lusiak-Szelachowska, M.; Gorski, A. Bacteriophage procurement for therapeutic purposes. Front. Microbiol. 2016, 7, 1177. [CrossRef]

20. Azeredo, J.; Sillankorva, S.; Pires, D.P. Pseudomonas bacteriophage isolation and production. Methods Mol. Biol. 2014, 1149, 23-32.

21. Garbe, J.; Wesche, A.; Bunk, B.; Kazmierczak, M.; Selezska, K.; Rohde, C.; Sikorski, J.; Rohde, M.; Jahn, D.; Schobert, M. Characterization of jg024, a pseudomonas aeruginosa pb1-like broad host range phage under simulated infection conditions. BMC Microbiol. 2010, 10, 301. [CrossRef] 
22. Garbe, J.; Bunk, B.; Rohde, M.; Schobert, M. Sequencing and characterization of pseudomonas aeruginosa phage jg004. BMC Microbiol. 2011, 11, 102. [CrossRef]

23. Russell, J.F.S.D.W. Molecular Cloning: A Laboratory Manual, 3rd ed.; Cold Spring Harbor Laboratory Press: Cold Spring Harbor, NY, USA, 2001.

24. Kutter, E. Phage host range and efficiency of plating. Methods Mol. Biol. 2009, 501, 141-149.

25. Essoh, C.; Blouin, Y.; Loukou, G.; Cablanmian, A.; Lathro, S.; Kutter, E.; Thien, H.V.; Vergnaud, G.; Pourcel, C. The susceptibility of pseudomonas aeruginosa strains from cystic fibrosis patients to bacteriophages. PLOS ONE 2013, 8, e60575. [CrossRef]

26. Park, M.; Lee, J.H.; Shin, H.; Kim, M.; Choi, J.; Kang, D.H.; Heu, S.; Ryu, S. Characterization and comparative genomic analysis of a novel bacteriophage, sfp10, simultaneously inhibiting both salmonella enterica and escherichia coli o157:H7. Appl. Environ. Microbiol. 2012, 78, 58-69. [CrossRef]

27. Thurber, R.V.; Haynes, M.; Breitbart, M.; Wegley, L.; Rohwer, F. Laboratory procedures to generate viral metagenomes. Nat. Protoc. 2009, 4, 470-483. [CrossRef]

28. Jackman, S.D.; Vandervalk, B.P.; Mohamadi, H.; Chu, J.; Yeo, S.; Hammond, S.A.; Jahesh, G.; Khan, H.; Coombe, L.; Warren, R.L.; et al. Abyss 2.0: Resource-efficient assembly of large genomes using a bloom filter. Genome Res. 2017, 27, 768-777. [CrossRef]

29. Chevreux, B.W.; Wetter, T.; Suhai, S. Genome sequence assembly using trace signals and additional sequence information. In Proceedings of the German Conference on Bioinformatics (GCB), Hannover, Germany, 4-6 October 1999; Volume 99, pp. 45-56.

30. Garneau, J.R.; Depardieu, F.; Fortier, L.C.; Bikard, D.; Monot, M. Phageterm: A tool for fast and accurate determination of phage termini and packaging mechanism using next-generation sequencing data. Sci. Rep. 2017, 7, 8292. [CrossRef]

31. Brettin, T.; Davis, J.J.; Disz, T.; Edwards, R.A.; Gerdes, S.; Olsen, G.J.; Olson, R.; Overbeek, R.; Parrello, B.; Pusch, G.D.; et al. Rasttk: A modular and extensible implementation of the rast algorithm for building custom annotation pipelines and annotating batches of genomes. Sci. Rep. 2015, 5, 8365. [CrossRef]

32. Overbeek, R.; Olson, R.; Pusch, G.D.; Olsen, G.J.; Davis, J.J.; Disz, T.; Edwards, R.A.; Gerdes, S.; Parrello, B.; Shukla, M.; et al. The seed and the rapid annotation of microbial genomes using subsystems technology (rast). Nucleic Acids Res. 2014, 42, D206-D214. [CrossRef]

33. Aziz, R.K.; Bartels, D.; Best, A.A.; DeJongh, M.; Disz, T.; Edwards, R.A.; Formsma, K.; Gerdes, S.; Glass, E.M.; Kubal, M.; et al. The rast server: Rapid annotations using subsystems technology. BMC Genom. 2008, 9, 75. [CrossRef]

34. Delcher, A.L.; Bratke, K.A.; Powers, E.C.; Salzberg, S.L. Identifying bacterial genes and endosymbiont DNA with glimmer. Bioinformatics 2007, 23, 673-679. [CrossRef]

35. Besemer, J.; Lomsadze, A.; Borodovsky, M. Genemarks: A self-training method for prediction of gene starts in microbial genomes. Implications for finding sequence motifs in regulatory regions. Nucleic Acids Res. 2001, 29, 2607-2618. [CrossRef]

36. Lowe, T.M.; Chan, P.P. Trnascan-se on-line: Integrating search and context for analysis of transfer rna genes. Nucleic Acids Res. 2016, 44, W54-W57. [CrossRef]

37. Nakamura, T.; Yamada, K.D.; Tomii, K.; Katoh, K. Parallelization of mafft for large-scale multiple sequence alignments. Bioinformatics 2018, 34, 2490-2492. [CrossRef]

38. Castresana, J. Selection of conserved blocks from multiple alignments for their use in phylogenetic analysis. Mol. Biol. Evol. 2000, 17, 540-552. [CrossRef]

39. Stamatakis, A. Raxml version 8: A tool for phylogenetic analysis and post-analysis of large phylogenies. Bioinformatics 2014, 30, 1312-1313. [CrossRef]

40. Kumar, S.; Stecher, G.; Tamura, K. Mega7: Molecular evolutionary genetics analysis version 7.0 for bigger datasets. Mol. Biol. Evol. 2016, 33, 1870-1874. [CrossRef]

41. Boulanger, P. Purification of bacteriophages and sds-page analysis of phage structural proteins from ghost particles. Methods Mol. Biol. 2009, 502, 227-238.

42. Kropinski, A.M. Practical advice on the one-step growth curve. Methods Mol. Biol. 2018, 1681, 41-47.

43. Danis-Wlodarczyk, K.; Olszak, T.; Arabski, M.; Wasik, S.; Majkowska-Skrobek, G.; Augustyniak, D.; Gula, G.; Briers, Y.; Jang, H.B.; Vandenheuvel, D.; et al. Characterization of the newly isolated lytic bacteriophages ktn6 and kt28 and their efficacy against pseudomonas aeruginosa biofilm. PLoS ONE 2015, 10, e0127603. 
44. Coffey, B.M.; Anderson, G.G. Biofilm formation in the 96-well microtiter plate. Methods Mol. Biol. 2014, 1149, 631-641.

45. Smith, K.; Perez, A.; Ramage, G.; Gemmell, C.G.; Lang, S. Comparison of biofilm-associated cell survival following in vitro exposure of meticillin-resistant staphylococcus aureus biofilms to the antibiotics clindamycin, daptomycin, linezolid, tigecycline and vancomycin. Int. J. Antimicrob. Agents 2009, 33, 374-378. [CrossRef]

46. Chaturongakul, S.; Ounjai, P. Phage-host interplay: Examples from tailed phages and gram-negative bacterial pathogens. Front. Microbiol. 2014, 5, 442. [CrossRef]

47. Parmar, K.M.; Gaikwad, S.L.; Dhakephalkar, P.K.; Kothari, R.; Singh, R.P. Intriguing interaction of bacteriophage-host association: An understanding in the era of omics. Front. Microbiol. 2017, 8, 559. [CrossRef] [PubMed]

48. Ando, H.; Lemire, S.; Pires, D.P.; Lu, T.K. Engineering modular viral scaffolds for targeted bacterial population editing. Cell Syst. 2015, 1, 187-196. [CrossRef]

49. Le, S.; He, X.; Tan, Y.; Huang, G.; Zhang, L.; Lux, R.; Shi, W.; Hu, F. Mapping the tail fiber as the receptor binding protein responsible for differential host specificity of pseudomonas aeruginosa bacteriophages pap1 and jg004. PLoS ONE 2013, 8, e68562. [CrossRef] [PubMed]

50. Abedon, S.T. Phage evolution and ecology. Adv. Appl. Microbiol. 2009, 67, 1-45.

51. Deghorain, M.; Van Melderen, L. The staphylococci phages family: An overview. Viruses 2012, 4, 3316-3335. [CrossRef] [PubMed]

52. Essoh, C.; Latino, L.; Midoux, C.; Blouin, Y.; Loukou, G.; Nguetta, S.P.; Lathro, S.; Cablanmian, A.; Kouassi, A.K.; Vergnaud, G.; et al. Investigation of a large collection of pseudomonas aeruginosa bacteriophages collected from a single environmental source in abidjan, cote d'ivoire. PLoS ONE 2015, 10, e0130548. [CrossRef]

53. Young, R.; Gill, J.J. Microbiology. Phage therapy redux —What is to be done? Science 2015, 350, 1163-1164. [CrossRef]

54. Rohde, C.; Resch, G.; Pirnay, J.P.; Blasdel, B.G.; Debarbieux, L.; Gelman, D.; Gorski, A.; Hazan, R.; Huys, I.; Kakabadze, E.; et al. Expert opinion on three phage therapy related topics: Bacterial phage resistance, phage training and prophages in bacterial production strains. Viruses 2018, 10, 178. [CrossRef] [PubMed]

55. Betts, A.; Vasse, M.; Kaltz, O.; Hochberg, M.E. Back to the future: Evolving bacteriophages to increase their effectiveness against the pathogen pseudomonas aeruginosa pao1. Evol. Appl. 2013, 6, 1054-1063.

56. Uchiyama, J.; Suzuki, M.; Nishifuji, K.; Kato, S.I.; Miyata, R.; Nasukawa, T.; Yamaguchi, K.; Takemura-Uchiyama, I.; Ujihara, T.; Shimakura, H.; et al. Analyses of short-term antagonistic evolution of pseudomonas aeruginosa strain pao1 and phage kpp22 (myoviridae family, pb1-like virus genus). Appl. Environ. Microbiol. 2016, 82, 4482-4491. [CrossRef] [PubMed]

57. Rossitto, M.; Fiscarelli, E.V.; Rosati, P. Challenges and promises for planning future clinical research into bacteriophage therapy against pseudomonas aeruginosa in cystic fibrosis. An argumentative review. Front. Microbiol. 2018, 9, 775. [CrossRef]

58. Vieira, A.; Silva, Y.J.; Cunha, A.; Gomes, N.C.; Ackermann, H.W.; Almeida, A. Phage therapy to control multidrug-resistant pseudomonas aeruginosa skin infections: In vitro and ex vivo experiments. Eur. J. Clin. Microbiol. Infect. Dis. 2012, 31, 3241-3249. [CrossRef] [PubMed]

59. Alemayehu, D.; Casey, P.G.; McAuliffe, O.; Guinane, C.M.; Martin, J.G.; Shanahan, F.; Coffey, A.; Ross, R.P.; Hill, C. Bacteriophages phimr299-2 and phinh-4 can eliminate pseudomonas aeruginosa in the murine lung and on cystic fibrosis lung airway cells. mBio 2012, 3, e00029-12. [CrossRef]

60. Beeton, M.L.; Alves, D.R.; Enright, M.C.; Jenkins, A.T. Assessing phage therapy against pseudomonas aeruginosa using a galleria mellonella infection model. Int. J. Antimicrob Agents 2015, 46, 196-200. [CrossRef]

61. Debarbieux, L.; Leduc, D.; Maura, D.; Morello, E.; Criscuolo, A.; Grossi, O.; Balloy, V.; Touqui, L. Bacteriophages can treat and prevent pseudomonas aeruginosa lung infections. J. Infect. Dis. 2010, 201, 1096-1104. [CrossRef] [PubMed]

62. Henry, M.; Lavigne, R.; Debarbieux, L. Predicting in vivo efficacy of therapeutic bacteriophages used to treat pulmonary infections. Antimicrob Agents Chemother. 2013, 57, 5961-5968. [CrossRef] 
63. Ceyssens, P.J.; Miroshnikov, K.; Mattheus, W.; Krylov, V.; Robben, J.; Noben, J.P.; Vanderschraeghe, S.; Sykilinda, N.; Kropinski, A.M.; Volckaert, G.; et al. Comparative analysis of the widespread and conserved pb1-like viruses infecting pseudomonas aeruginosa. Environ. Microbiol. 2009, 11, 2874-2883. [CrossRef]

64. Latz, S.; Kruttgen, A.; Hafner, H.; Buhl, E.M.; Ritter, K.; Horz, H.P. Differential effect of newly isolated phages belonging to pb1-like, phikz-like and luz24-like viruses against multi-drug resistant pseudomonas aeruginosa under varying growth conditions. Viruses 2017, 9, 315. [CrossRef] [PubMed]

(C) 2019 by the authors. Licensee MDPI, Basel, Switzerland. This article is an open access article distributed under the terms and conditions of the Creative Commons Attribution (CC BY) license (http://creativecommons.org/licenses/by/4.0/). 